\title{
Treadmill Locomotion in the Intact and Spinal Mouse
}

\author{
Hugues Leblond, Marion L'Espérance, Didier Orsal, and Serge Rossignol \\ Centre de Recherche en Sciences Neurologiques, Department of Physiology, Université de Montréal, Montréal, Quebec, Canada H3T 1J4
}

Because the genetic characteristics of several inbred strains of mice are well identified, their use is becoming increasingly popular in spinal cord injury research. In this context, it appears particularly important to document adequately motor patterns, such as locomotion in normal mice, to establish some baseline values of locomotor characteristics. It also seems crucial to determine the extent to which mice can express a locomotor pattern after a complete spinal transection to establish a baseline on which one can evaluate the effects of treatments after spinal injury. Therefore, we have used conventional techniques to document the kinematics of treadmill locomotion in intact mice $(n=11)$ and in mice with a complete section of the spinal cord at T8 $(n=12)$. The results show that the kinematics and EMG of adult normal mice can be adequately monitored with such conventional equipment and that mice can re-express hindlimb locomotion within $14 \mathrm{~d}$ after spinalization, without any pharmacological treatments. The angular excursions of the hip, knee, and ankle are similar to those of the intact mice, although the joints are sometimes more flexed. After spinal cord transection, out-of-phase alternation between the homologous limbs recovered, whereas the timing between homolateral limbs was completely lost. This remarkable ability of mice to express hindlimb locomotion after a complete spinalization should be taken into account in the evaluation of various procedures aimed at promoting the functional recovery of locomotion after spinal lesions.

Key words: spinal mouse; locomotion; functional recovery; central pattern generator; electromyography; kinematics; spinal cord injury

\section{Introduction}

The ability of the lumbosacral spinal cord to generate locomotor movements of the hindlimbs after a low thoracic spinal section has been shown in many species (Delcomyn, 1980; Grillner, 1981). This has been particularly studied in cats after a complete section at T13 (Forssberg et al., 1980; Barbeau and Rossignol, 1987; Lovely et al., 1990; Bélanger et al., 1996; Rossignol, 1996; Rossignol et al., 2002). In contrast, adult rats are not able to re-express sustained locomotion with their hindlimbs after a spinal lesion unless drugs or other treatments are used (Broton et al., 1996; McDonald et al., 1999; Gimenez y Ribotta et al., 2000; Antri et al., 2002; Orsal et al., 2002). However, rats spinalized as neonates can walk with their hindlimbs on a treadmill (de Leon et al., 2002).

Because the genetic characteristics of several inbred strains of mice are well identified, they are becoming increasingly popular in spinal cord injury research (Steward et al., 1999). An in vitro preparation of neonatal mouse is currently used (for review, see Bonnot et al., 2002b) to study rhythmic behaviors in the spinal cord (Hernandez et al., 1991; Tao and Droge, 1992; Droge and

Received June 4, 2003; revised 0ct. 9, 2003; accepted 0ct. 10, 2003.

H.L. and this work were supported by a Tier 1 Canada Research Chair on Spinal Cord (to S.R.). M.L. was supported by a Summer studentship from the Faculty of Medicine, and the collaboration with D.0. was supported by the Christopher Reeve Paralysis Foundation. We acknowledge the participation of Dr. P. Guertin in some of the experiments. We thank Dr. L. McKerracher and P. Dergham for introducing us to the spinal mouse model and J. Provencher, F. Lebel, P. Drapeau, C. Gagner, and S. Cabana for their competent help in this work.

Correspondence should be addressed to Dr. Serge Rossignol, Centre de Recherche en Sciences Neurologiques, Pavillon Paul-G.-Desmarais, 2960 Chemin de la Tour, Université de Montréal, Montréal, Québec, Canada H3T 1J4. E-mail:Serge.Rossignol@umontreal.ca.

D. Orsal's present address: Université Pierre et Marie Curie, Institut de Biologie Intégrative (IFR83), Laboratoire de Neurobiologie des Signaux Intercellulaires, Centre National de la Recherche Scientifique, Unité Mixte de Recherche 7101, 7 quai Saint Bernard, F-75252 Paris Cedex 05, France.

Copyright $\odot 2003$ Society for Neuroscience $\quad$ 0270-6474/03/2311411-09\$15.00/0
Tao, 1993; Bonnot et al., 1998; Jiang et al., 1999; Branchereau et al., 2000; Whelan et al., 2000) or to identify the neural components of spinal networks using calcium imaging techniques (Bonnot et al., 2002a). However, surprisingly, a detailed description of the kinematics of locomotion in adult normal and spinal mice is still lacking (Fortier et al., 1987; Hernandez et al., 1991; Clarke and Still, 1999, 2001). The small size of the mouse is an obvious setback when using conventional EMG and kinematic methods. This explains why behavioral tests relying on visual observations in open-field conditions, such as those developed to evaluate locomotion in rats after spinal cord injuries (Basso et al., 1995), are also used with mice (Farooque, 2000; Dergham et al., 2002; Seitz et al., 2002). However, this is not always sufficient to assess the recovery of locomotion after spinal lesions (Kunkel-Bagden et al., 1993; Broton et al., 1996; Van de Meent et al., 1996). In an open-field situation, in which animals move around with their forelimbs, it is important to know to what extent the isolated lumbar cord can produce locomotor movements when nonspecific stimulation of the abdomen or the tail is provided as a consequence of these forelimb movements. For instance, in the spinal cat, nonspecific stimulation of the perineum or the abdomen can trigger locomotor movements (Barbeau and Rossignol, 1987). In the best cases, such triggered hindlimb movements may appear coordinated with forelimb movements if not properly measured. Furthermore, it is important to document with appropriate kinematic and EMG recordings that these movements are locomotor as opposed to other forms of isolated kicks of the hindlimbs.

Thus, we propose here to determine first, the main characteristics of murine locomotion on a treadmill, and second, to what extent mice can express a locomotor pattern after a complete 
spinal transection. Some of the results have been reported previously in abstract form (Leblond et al., 2002).

\section{Materials and Methods}

General protocol. Adult male and female mice $(n=23)$, weighing $25-30$ gm, of three strains (CD1, $n=14 ; \mathrm{BALB} / \mathrm{c}, n=4 ; \mathrm{C} 57 \mathrm{BL} / 6, n=3$ ) were used in this study. A first group of mice $(n=10: 3 \mathrm{CD} 1,4 \mathrm{BALB} / \mathrm{c}, 3$ C57BL/6) were trained to walk on a motor driven treadmill belt at constant speed $(0.07-0.2 \mathrm{~m} / \mathrm{sec})$ for periods of 5 min twice daily, to obtain baseline values for locomotion in the intact state. A second group of mice (CD1, $n=$ 13) were spinalized at the T8 level under general anesthesia to assess their locomotor capabilities after a complete section of the spinal cord. Within the latter group, 11 mice were then trained to walk on the treadmill for 5 min twice daily as the control group, and 2 mice were not trained at all.

Surgical procedure. All surgeries were performed under aseptic conditions. In a first group of animals, general anesthesia consisted of $4 \%$ Hypnorm (fentanyl citrate fluonisone, $8 \mu \mathrm{g} / \mathrm{gm}$ ) in combination with $1 \%$ Versed (midazolam, $5 \mu \mathrm{g} / \mathrm{gm}$ ) given intraperitoneally. However, we found that the postoperative survival rate was much better in the second group, which was anesthetized with $2 \%$ isoflurane in a mixture of $95 \% \mathrm{O}_{2}$ and $5 \% \mathrm{CO}_{2}$ given through a mask. The benefit of using gas anesthesia (isoflurane) lies in its fast elimination after the surgery; as a result, the mice recover quickly 2-3 min after the removal of the mask. For analgesia, buprenorphin $(0.1 \mu \mathrm{g} / \mathrm{gm})$ was given subcutaneously postoperatively twice daily for $2 \mathrm{~d}$. To prevent infection, enroflacin (Baytril, 5 $\mu \mathrm{g} / \mathrm{gm}$ ) was administered subcutaneously for $5 \mathrm{~d}$. After surgery, the mice were kept for $2-3 \mathrm{hr}$ under a heating lamp until they regained consciousness; they were kept in their individual cages and provided with sufficient food and water supplies. The well being of the mice was always ensured and all procedures followed a protocol approved by the Ethics Committee at Université de Montréal, according to the Canadian Guide for the Care and Use of Experimental Animals.

Implantation. In one mouse, EMG recording electrodes were implanted in different hindlimb muscles under general anesthesia. A 10-pin custom-made connector (Nano series; Omnetics Connector Corporation, Minneapolis, MN) measuring $1.7 \times 6.0 \times 4.0 \mathrm{~mm}$ was sutured on the back of the mouse at the thoracic level. Four pairs of flexible miniature (nominal overall diameter, $0.28 \mathrm{~mm}$ ) hygroscopic fluorocarboninsulated stainless steel wires (AS631; Cooner Wire, Chatsworth, CA) previously soldered onto the pins of the connector were led subcutaneously and implanted, in pairs, in the following muscles: right and left vastus lateralis (RVL and LVL) and right and left tibialis anterior (RTA and LTA) in the hindlimbs. A pair of wires from the connector was placed under the skin to serve as an electrical ground. The overall weight of the connector and wires was $\sim 0.30 \mathrm{gm}$.

Spinalization. Under general anesthesia, the back of the mouse was shaved and disinfected with proviodine [iodine complexed with povidone (polyvinyl-pyrrolidone)] at the incision site. Skin and muscles were cut from T6 to T12 $(\sim 1 \mathrm{~cm})$ with a fine scalpel, and a laminectomy was performed at the eighth thoracic vertebra. Lidocaine (xylocaine $2 \%$ without epinephrine) was applied on the cord at the site identified for the lesion, to prevent brisk movements that could lead to a larger spinal lesion. A homemade hook was first carefully inserted beneath the exposed cord before it was surgically transected with fine scissors. To ensure completeness of the transection, the hook was then lifted through the lesion. To prevent bleeding, a piece of sterile absorbable hemostat (Surgicel; Ethicon, Somerville, NJ) was placed in the space between the caudal and the rostral portions of the spinal cord. Muscles and skin were then sutured and the mice placed in their respective cage under a heating lamp, as described above. For the first week after spinalization, manual bladder expression was performed twice daily and the hindquarters of the mice were cleaned carefully to avoid infection. At 6-7 d after surgery, spontaneous micturition usually returned. The animals had no significant health problems for months after spinalization except for an initial loss of body weight of $16 \pm 6 \%$ (mean \pm SD).

Recording and analysis procedures. Locomotion in the intact state was recorded while the animal walked freely at different speeds imposed by the treadmill belt. A special Plexiglas enclosure, $5 \times 15 \times 13 \mathrm{~cm}$, with a removable top, was placed over the treadmill belt, to limit lateral move- ments and reduce parallax errors. To evaluate spinal locomotion, the mice were placed over a treadmill belt either (1) with the two forelimbs placed on a platform located $1 \mathrm{~cm}$ above the belt while the hindlimbs were placed over the running treadmill or (2) with all four limbs on the moving treadmill. Calibration markers (5 $\mathrm{cm}$ distance) were placed on the Plexiglas enclosure. Pieces of reflective markers $(1.5 \times 1.5 \mathrm{~mm})$ were placed on the shaved skin of the left hindlimb at the iliac crest, the femoral head, the knee joint, the ankle joint, and over the metatarsophalangeal joint. In some cases, the mice had to be anesthetized with isoflurane $(2 \%)$ before the markers could be placed precisely on the left hindlimb. They recovered very quickly after removal of the anesthesia (2-3 $\mathrm{min}$ ), as witnessed by their ability to walk normally after $\sim 5 \mathrm{~min}$.

Because the aim of this study was to show that the spinal animals could produce hindlimb stepping on the treadmill, we optimized the positioning of the hindlimbs for maximal weight support by holding the tail of the mouse. The only way to ensure a constant weight support would have been to use a mechanical device that could measure the amount of weight support provided. Unfortunately, we do not know of any device that can optimize the positioning of the limbs for each animal. In spinal cats, we decided against the use of devices that can themselves exert an inhibitory effect by stimulating the back region or the groin.

A side view of each mouse walking on the treadmill was captured, using a National Television System Committee Panasonic 5100 camera (shutter speed 1/1000 sec; Panasonic, Secaucus, NJ) at 30 frames per second and recorded on videotape (Panasonic AG 7300 recorder). Selected sequences were digitized and the frames de-interlaced, which yielded a time resolution of 60 fields per second ( $16.6 \mathrm{msec}$ between fields) for analysis of the limb kinematics.

Custom-designed video analysis software was used to extract the $x$ and $y$ coordinates of the different joint markers, to obtain angular excursions of the joints. An evaluation of the measurement error was made by using two reflective markers $(1.5 \times 1.5 \mathrm{~mm}$; i.e., the same dimensions as the markers used on mice), separated by a known distance $(0.82 \mathrm{~cm})$ on a black cardboard. The cardboard was moved randomly in front of the camera and recorded for $36 \mathrm{sec}$. The mean length \pm SD obtained from the acquisition of the 2200 fields was $0.82 \pm 0.03 \mathrm{~cm}$ for an error of $<3.5 \%$. Therefore, we are confident that the recording system, which uses markers and a video camera, is appropriate to measure the kinematics of the mouse during treadmill locomotion.

Foot contact and foot lift for each limb of the animal were identified, with a time resolution of one video field, by the experimenter. These measurements allowed the establishment of the duration of the step cycle (see Fig. 1), the coupling between limbs (Fig. $3 B-D$ ) and the gait diagrams (Hildebrand, 1976) of the mouse (see Figs. $3 A, 4 A, B, 7,8$ ). Identified events, such as foot contacts and foot lifts, were used to trigger averages of angular excursions of the limb (see Figs. $2 B, D, 5 D-F, 6$ ) or average EMGs (see Fig. $4 A, B$ ). Also, stick diagram representation of the hindlimb were made (see Figs. $2 A, C, 4 C, 5 A-C$ ) to illustrate the step cycle of the mouse. To minimize errors that may result from skin slippage at the knee, the knee point was extrapolated. Knowing the exact X-Y position of the hip and ankle joints as well as the length of the femur and of the tibia, the position of the knee can be obtained by triangulation. EMG signals were differentially amplified (bandwidth, $100 \mathrm{~Hz}$ to $3 \mathrm{kHz}$ ) and digitized with a data acquisition board at $1 \mathrm{kHz}$, directly on a personal computer. Video and EMG acquisition were synchronized by means of an external module linked to a Society of Motion Picture and Television Engineers time code generator/ reader (model TCG-80N; Skotel, Brossard, Quebec, Canada).

Statistical comparisons between intact and spinal mice were made using a Student's $t$ test to determine the $p$ value. Circular statistics (Zar, 1996) were used to determine the phase value between the hindlimbs and the forelimbs of the intact mouse (see Fig. 8D), to compare intact and spinal animals. This method and its graphical representation have been described previously (Kjaerulff and Kiehn, 1996).

\section{Results}

\section{Step cycle of the intact mouse}

The step cycle can be subdivided into stance and swing phases. The stance phase begins as soon as the foot contacts the ground and ends when the foot starts its forward movement. The swing 
Table 1. Averaged step cycle duration and coupling phases in intact mice

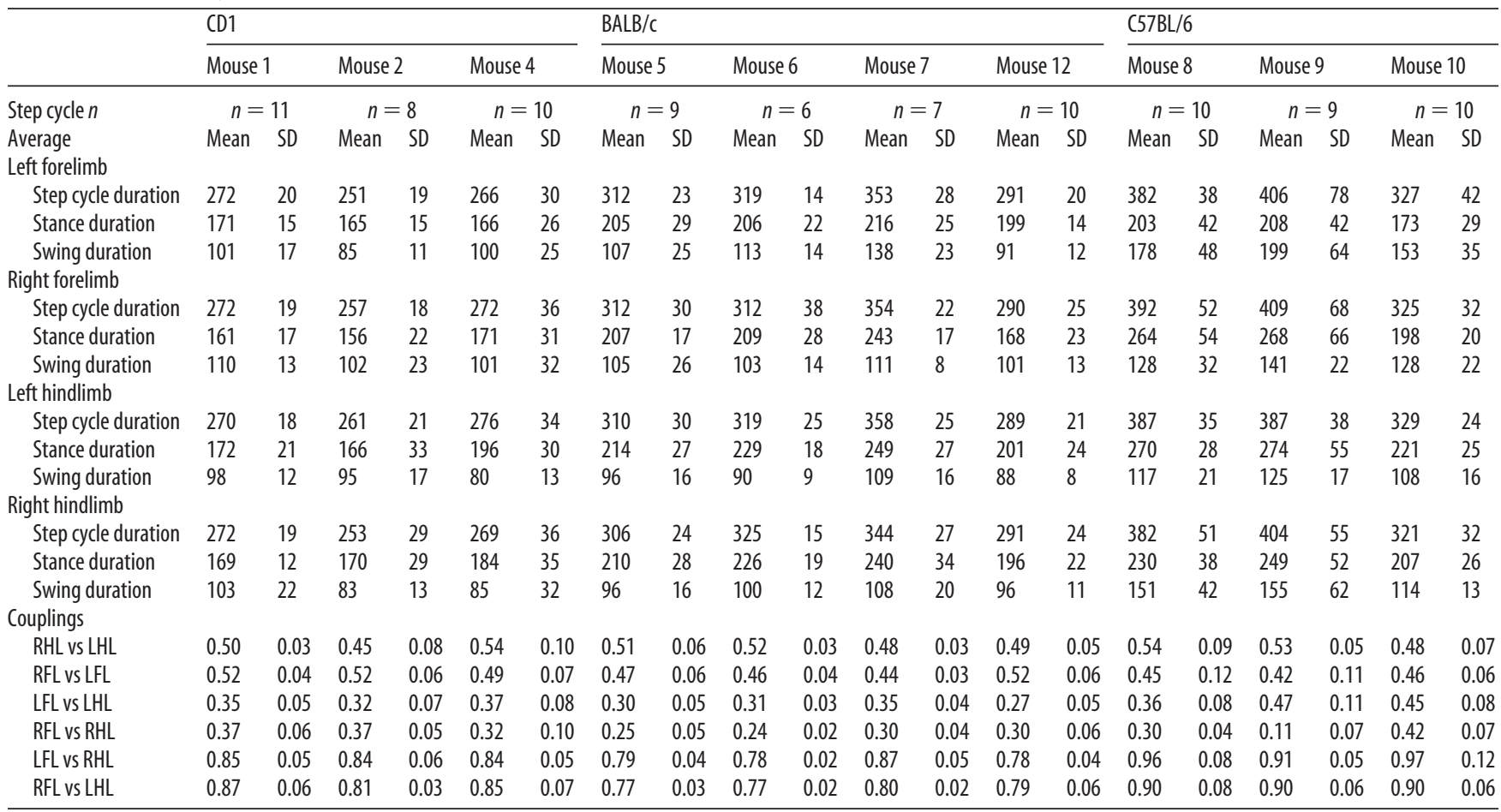

Values except for number of cycles are means \pm SD expressed in milliseconds for 10 intact mice of three different strains.

phase begins, not necessarily with the paw lift (because of a possibility of a paw drag), but at the onset of forward movement of the foot and ends as it touches the treadmill belt again. The duration of the step cycle, as well as the duration of the stance and swing phases, were measured at different treadmill speeds in 10 intact mice of three different strains: 3 CD1 (average weight, 29 gm), $4 \mathrm{BALB} / \mathrm{c}$ (average weight, $19 \mathrm{gm}$ ) and $3 \mathrm{C} 57 \mathrm{BL} / 6$ (average weight, $20 \mathrm{gm}$ ). The average values for each individual are summarized in Table 1 and illustrated in Figure $1 A$ for a treadmill speed of $0.15 \mathrm{~m} / \mathrm{sec}$. Figure $1 A$ clearly shows that the average step cycle duration differs somewhat for each strain, ranging from $253 \pm 29(\mathrm{CD} 1)$ to $403 \pm 55 \mathrm{msec}(\mathrm{C} 57 \mathrm{BL} / 6)$. However, for a given mouse, each consecutive step cycle duration was constant (small SD) at this treadmill speed, especially for the CD1 strain. Mice had difficulty maintaining a regular step cycle at treadmill speeds lower than $0.15 \mathrm{~m} / \mathrm{sec}$. Note that the swing phase was comparable between each strains, whereas the duration of the stance phase varied in accordance with the duration of the step cycle.

Figure $1 B$ shows a typical example of the average step cycle obtained for a mouse (Mouse 8 ) walking at three different treadmill speeds $(0.1,0.15$, and $0.2 \mathrm{~m} / \mathrm{sec})$. The duration of the stance phase decreased with speed, whereas the swing phase was almost invariant. These results illustrate not only a typical characteristic of locomotion but also show that the mouse can be trained to walk at different constant speeds on the treadmill. As the treadmill speed increases from 0.1 to $0.2 \mathrm{~m} / \mathrm{sec}$, the average duration of the step cycle (mean of more than six cycles) decreased from $484 \pm 94$ to $323 \pm 35 \mathrm{msec}$ (Fig. $1 B$ ). The larger SD at $0.1 \mathrm{~m} / \mathrm{sec}$ denotes, as mentioned previously, that the animal had some difficulty maintaining the same pace at such a slow treadmill speed. The duration of the swing phase remained almost constant, $\sim 112 \pm 23 \mathrm{msec}$, whereas the duration of the stance phase decreased as the mouse walked faster, from an average of $370 \pm 62$ $\mathrm{msec}$ at $0.1 \mathrm{~m} / \mathrm{sec}$ to $211 \pm 40 \mathrm{msec}$ at $0.2 \mathrm{~m} / \mathrm{sec}$.

\section{A. $0.15 \mathrm{~m} / \mathrm{s}$}

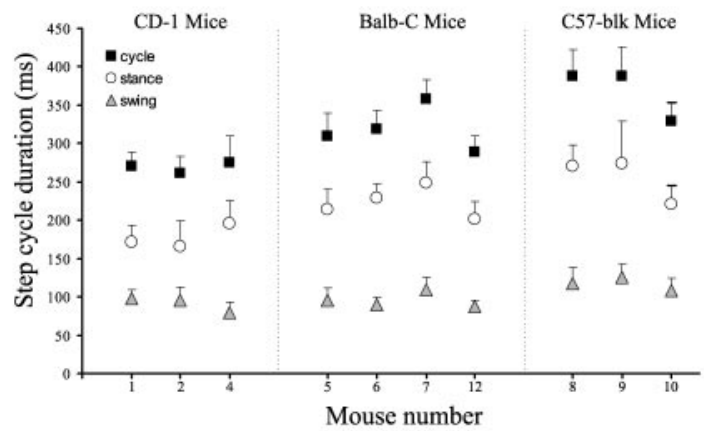

B. Increasing treadmill speeds

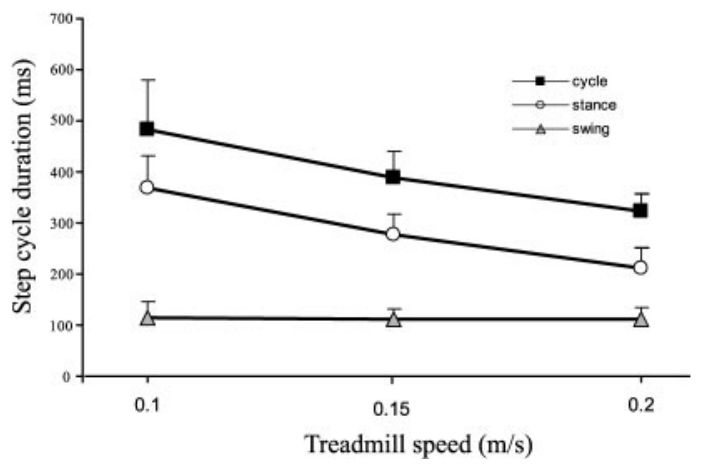

Figure 1. Average step cycle duration of the intact mouse. A, Averaged duration of the step cycle (black squares), the stance phase (circles), and the swing phase (triangles) for 10 mice from three different strains at a treadmill speed of $0.15 \mathrm{~m} / \mathrm{sec}$. $B$, Typical example of the averaged duration of the step cycle (black squares), the stance phase (circles), and the swing phase (triangles) for a mouse (mouse number 8 ) at three different treadmill speeds. 
$0.1 \mathrm{~m} / \mathrm{s}$

A

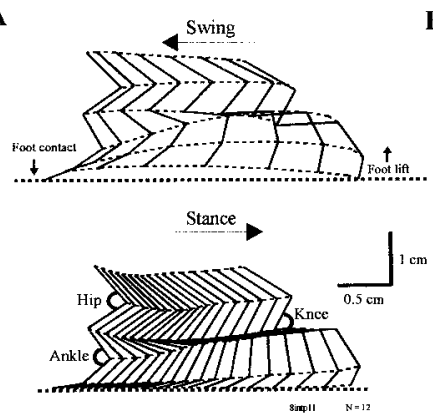

B

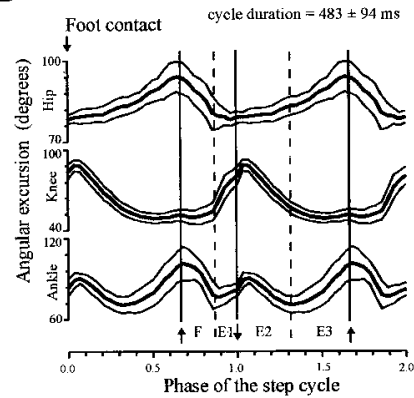

C

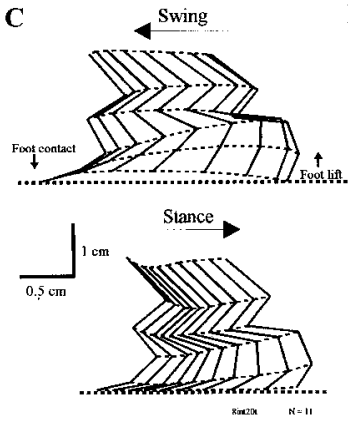

$0.2 \mathrm{~m} / \mathrm{s}$

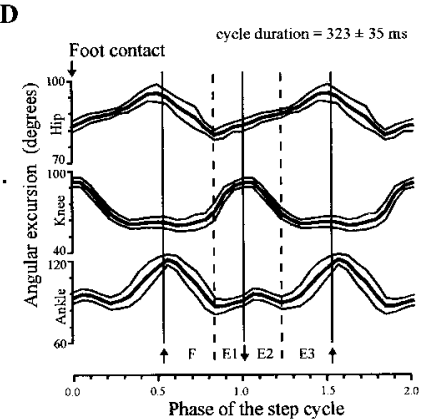

Figure 2. Kinematics of the intact mouse. $A-C$, Stick figures of one complete step cycle (swing and stance) of one hindlimb at two treadmill speeds: $0.1 \mathrm{~m} / \mathrm{sec}(A)$ and $0.2 \mathrm{~m} / \mathrm{sec}(C)$. The arrows above each set of stick figures indicate the direction of the movement. Downward arrows indicate foot contact and upward arrows indicate foot lift. The orientation for measurement of each joint is given. $B-D$, Angular excursions of three joints averaged over $>10$ cycles at the same two treadmill speeds: $0.1 \mathrm{~m} / \mathrm{sec}(B)$ and $0.2 \mathrm{~m} / \mathrm{sec}(D)$. All angle measurements were synchronized on left foot contact.

\section{Kinematics of the intact mouse}

Figure 2 illustrates the kinematics of the hindlimb of an intact mouse walking on a treadmill at two different treadmill speeds: $0.1 \mathrm{~m} / \mathrm{sec}$ (Fig. $2 A, B$ ) and $0.2 \mathrm{~m} / \mathrm{sec}$ (Fig. 2C,D). Walking is represented by (1) a stick diagram of one step cycle of the left hindlimb with the swing and stance phase drawn separately and (2) the angular displacement of the hip, knee, and ankle joints averaged over several consecutive step cycles $(n>10)$. The orientation of each joint measurement is indicated on the stick diagram (lower left-hand graph in $A$ ) and the display of angle excursions are synchronized on left foot contacts (downward arrows). The subdivisions of the step cycle defined by Philippson (1905) can be used to describe the various subphases of the murine step cycle. Note that downward deflections of the angular traces correspond to a flexion of the joints. The swing phase starts with a flexion $(\mathrm{F})$ of the hip and ankle while the knee remains at a constant angle, lifting the foot from the ground (upward arrows). Whereas the hip continues its flexion, the knee and ankle begin an extension (E1), which brings the paw in contact with the ground. As the paw contacts the ground (downward arrows), the knee and ankle are flexed (E2) while the hip begins its extension. Then, at $\sim 20 \%$ of the step cycle, the ankle starts an extension (E3; push off), which propels the body of the mouse forward. For this mouse, the average peak-to-peak angular excursions were $16^{\circ}$ at the hip, $34^{\circ}$ at the knee, and $28^{\circ}$ at the ankle. Similar angular excursions were observed at treadmill speeds of 0.15 (data not shown) and 0.2 $\mathrm{m} / \mathrm{sec}$ (Fig. $2 C-D$ ). Comparison of the stick diagram of the mouse walking at 0.1 (Fig. $2 A$ ) and $0.2 \mathrm{~m} / \mathrm{sec}$ (Fig. 2C) indicates that higher speed is obtained by reducing the length and the duration of the stance phase (i.e., there are fewer sticks during the stance phase in Fig. $2 C$ than in $2 A$ ). This difference also indicates that it is possible to impose a walking speed on the mice and that the step cycle can be constant at the chosen speeds.

\section{Interlimb coordination in the intact mouse}

The gait diagram of a duty cycle (Hildebrand, 1976) of the four limbs of the intact mouse during walking is illustrated in Fig. $3 \mathrm{~A}$. The horizontal bars represent stance phases of each limb, and the spaces correspond to the swing phases of an intact mouse walking on a treadmill at $0.15 \mathrm{~m} / \mathrm{sec}$. To illustrate how the coupling between the different limbs was calculated, a single cycle is highlighted in gray. Within this reference step cycle, three different couplings are measured: (1) coupling of the homolateral limbs [i.e., limbs on the same side of the animal (right or left)], (2) coupling of the homologous limbs [i.e., limbs on the same girdle of the animal (forelimbs or hindlimbs)], and (3) coupling of the diagonal limbs. For example, to estimate the value of the homologous coupling between the hindlimbs, we measured the time of the right foot contact (vertical dotted line indicated by arrow 2 in Fig. $3 A$ ) with respect to step cycle of the left hindlimb. When expressed as a percentage of the step cycle, the coupling interval between the left and the right hindlimb is $\sim 48 \%$ (or phase 0.48 ). For each step cycle, the same measurement was made for the homologous, homolateral, and diagonal limbs. The average coupling values were calculated and are shown in Table 1, as well as in Figure $3 B-D$ for all 10 mice studied.

Figure $3 B$ clearly shows that the homologous coupling between the RHL and the LHL, as well as between RFL and LFL were $\sim 50 \%$ for all mice tested at this treadmill speed. These numbers mean that at $0.15 \mathrm{~m} / \mathrm{sec}$, the limbs of each girdle step in strict alternation: the swing phase is followed half a step cycle later by the swing phase of the contralateral limb. Figure $3 C$ shows that the homolateral coupling between the LFL and LHL or between the RFL and RHL ranged from 25 to $45 \%$. This variability is not surprising because the different mice walked at different speeds (Fig. 1), and it is well known that the coupling between forelimbs and hindlimbs is more variable and is also speed-related (Hildebrand, 1976). Indeed, walking is characterized by the forelimb contacting the treadmill at $\sim 25 \%$ of the hindlimb step cycle, whereas during trot, the forelimb touches the treadmill at $50 \%$ of the hindlimb step cycle. Figure $3 D$ shows the diagonal couplings (i.e., coupling between LFL and RHL and coupling between RFL and LHL); the percentages ranged between 78 and 97\%.

\section{EMG activity during locomotion}

We were able to study the kinematics together with the synchronized EMGs in one chronically implanted mouse walking on a treadmill. Raw EMG traces obtained during locomotion, synchronized with the corresponding duty cycle of the hindlimbs, are shown in Figure $4 A$. For this mouse, the mean duration for 45 consecutive bursts of activity was $157 \pm 35 \mathrm{msec}$ for LVL, $120 \pm$ $28 \mathrm{msec}$ for RVL, $58 \pm 17 \mathrm{msec}$ for LTA, and $72 \pm 23 \mathrm{msec}$ for RTA. Comparing the timing with duty cycles given below the EMG traces, we see that the recordings of these muscles give a good indication of the swing and stance phases of the limbs. The knee extensors (LVL and RVL) were active during the stance phases of the hindlimbs, whereas the ankle flexors (LTA and 


\section{A. Duty cycle of an intact mouse}

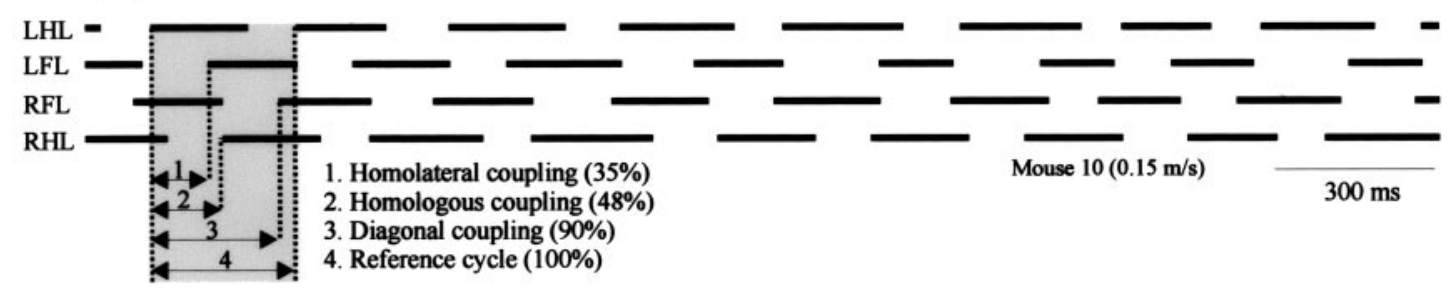

B. Homologous coupling

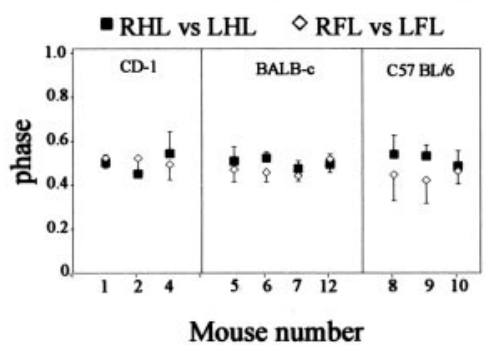

C. Homolateral coupling

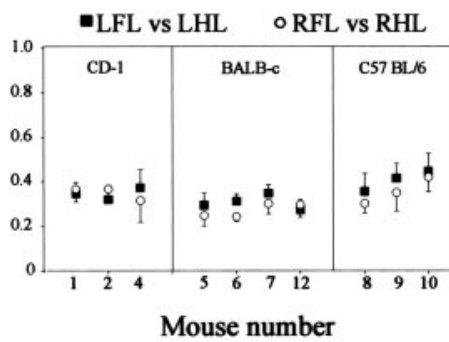

D. Diagonal coupling

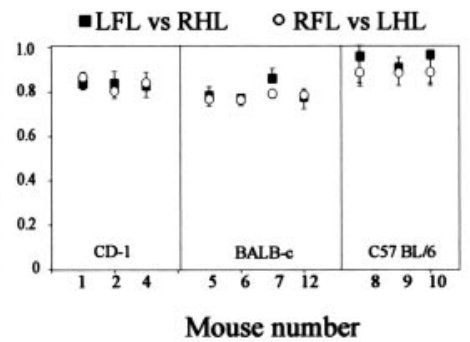

Figure 3. Coupling phases during locomotion in intact mice. A, Typical example of the duty cycle of a mouse (Mouse 10 ) at $0.15 \mathrm{~m} / \mathrm{sec}$, with an indication of how the different couplings between limbs was measured in the first step cycle (reference cycle). $B-D$, Homologous, homolateral, and diagonal couplings of a minimum of eight successive step cycles averaged for all intact mice tested during treadmill walking.

A)

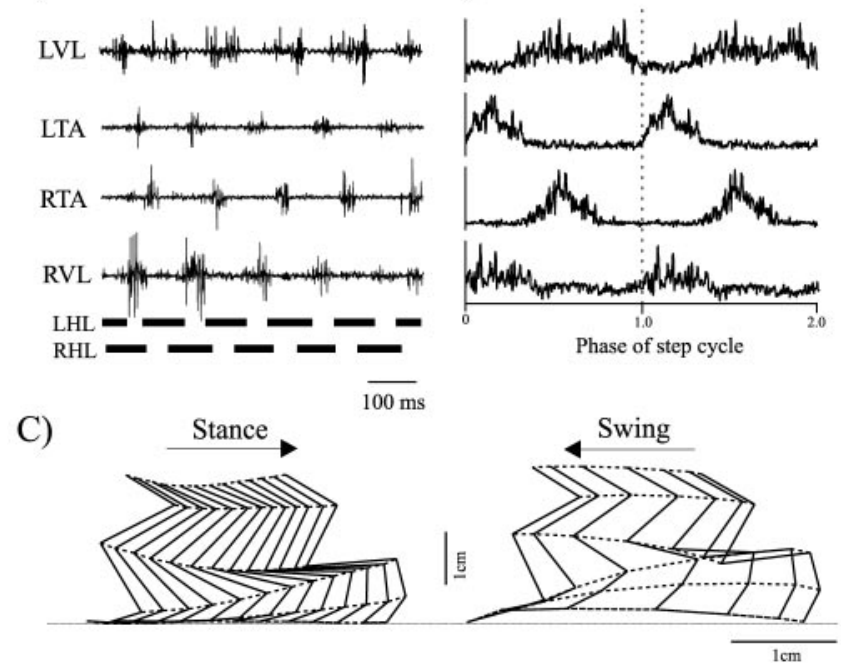

Figure 4. EMG traces of an intact mouse walking on a treadmill. $A$, Raw EMG bursts of activity during locomotion at a treadmill speed of $0.2 \mathrm{~m} / \mathrm{sec}$ of selected hindlimb muscles of the hindlimbs: LVL, RVL, LTA, RTA. The corresponding duty cycle is given below. $B$, Averaged ( $n=20)$ EMG envelopes, normalized with respect to time of the same muscles (repeated for two cycles). C, Representative stick figures for one step cycle of the implanted mouse.

RTA) were active during the swing phase of the step cycle of the corresponding hindlimb.

In Figure $4 B$, the EMG bursts were rectified, averaged over 20 consecutive step cycles and then normalized (synchronization on LTA) to illustrate the overall reciprocity between flexors and extensors, as well as between right and left sides of the animal. Indeed, within the same limb, there is good alternation between extensor and flexor muscles. Right-left alternation is also clear between both TAs and VLs.

Figure $4 C$ represents one step cycle of the implanted mouse during locomotion. Note that, even if the VL and TA muscles of both hindlimbs are implanted, the kinematics of the limb is similar to those of the nonimplanted mouse (compared with stick diagrams of Fig. 2), suggesting that the chronically implanted microwire used as well as the connector do not interfere with the ongoing movements. Thus, it will be possible in the future to routinely use chronically implanted EMG electrodes in the mouse to compare the locomotor pattern before and after a spinal lesion in the same animal.

\section{Recovery of locomotion in the spinal mouse}

Kinematics of the spinal mouse (intralimb coordination) In all mice tested $(n=11)$, there were generally no movements of the hindlimbs for the first 5-6 d after a complete section of the spinal cord at T8, even with strong stimulation of the tail or the perineal region. Movements of the hindlimbs usually started $6 \mathrm{~d}$ after the spinalization and consisted mainly of some occasional flexion of all joints, with limbs being dragged on the belt surface. This drag of the hindlimbs during the swing phase can be better appreciated in the stick diagram of Figure $5 \mathrm{~A}$. In this example, the animal was unable to clear the knee and/or the toes from the surface of the treadmill. Figure $5 D$ shows the raw angular excursions during a small number of consecutive but irregular flexions of all the joints. At this stage, no active extension of the hindlimbs was observed; the hindlimbs were just brought back by the treadmill movement after the flexion. The hindquarters of the mouse had to be supported by the experimenter (no plantar foot contact) and moderate cutaneous stimulation had to be applied at the proximal part of the tail to evoke these movements.

By the eighth day after spinalization, the mice increased the duration of their stance phase and began to show a certain weight support and, sometimes, placed the plantar surface of the paw on the treadmill (data not shown). An important paw drag was still observed in most of the swing phase, and there was no consistent alternation between hindlimbs.

At day 12 after spinalization, the mouse was able to place the foot further ahead in front of the hip, as shown in Figure $5 \mathrm{~B}$. Also evident in this figure is the foot that now clears the surface of the treadmill during the swing phase. A good weight support was maintained during the stance phase. Locomotion was elicited 
without any external stimulation, other than the treadmill movement; however, the balance of the animal had to be provided by holding the very end of its tail. The raw angular excursions of consecutive step cycles in Figure $5 E$ reveal that the timing of locomotion was much more regular at day 12 after spinalization. Also noteworthy in Figure $5 E$ is the overall increase in hip flexion (compared with day 6), which brings the animal in an upright position (Fig. 5, compare $A, B$ ).

To make sure that these locomotor patterns were not caused by some axonal regrowth, the spinal cord was completely cut for a second time in this mouse at exactly the same location as the first spinalization. The example in Figure $5 C$ illustrates the kinematics of the mouse $14 \mathrm{~d}$ after a first spinalization and $2 \mathrm{~d}$ after a second such section. In this case, there was no additional deficit observed after the second spinalization. Quite the contrary, the mouse continued to improve its locomotion, adding more regularity to the step cycle (Fig. $5 F$ ) and a better coordination between the right and left sides (see next section). Therefore, by itself, the spinal cord caudal to the lesion can generate the observed locomotor rhythm. At this stage, the average step duration of the left hindlimb of the spinal mouse was $696 \pm 61$ msec.

Overall, the hindlimb step cycle mean duration of spinal mice $(700 \pm 64 \mathrm{msec})$ was significantly higher $(p<0.0005)$ than that of intact mice $(500 \pm 94 \mathrm{msec})$. The longer step duration of the spinal mouse is caused mainly by a significantly higher $(p<$ $0.0005)$ mean duration of its stance phase, the duration of the swing phases not being significantly different. These differences are illustrated with typical examples of step cycles (compare Figs. $2 A, 5 C$ ) in which it is clear that there is a higher number of sticks representing the stance phase of the spinal mouse than during that of the intact mouse.

The regularity of the step cycle at $14 \mathrm{~d}$ after spinalization allowed us to perform averages of the angular excursions of the left hindlimb (Fig. 6). The overall angular displacement of the hip, knee, and ankle follow the same pattern as that of the intact animal (compare Fig. 2 B), except for the second ankle extension (E2) at the foot contact, which was often missing after spinalization. Note that, in contrast with the intact animal that can walk without any support, spinal mice had to be held up by the end of the tail, which might have led to a decrease in active weight support of the hindquarters, thus explaining the reduced E2 phase after foot contact. The average peak-to-peak angular excursion was $18^{\circ}$ at the hip, $17^{\circ}$ at the knee, and $26^{\circ}$ at the ankle.

A similar time course of recovery was obtained in 10 of the 13 spinal mice tested, including the 2 untrained mice; 1 mouse had virtually the same sequence of progress, but much later after spinalization ( $29 \mathrm{~d}$ instead of $14 \mathrm{~d}$ before recovery of locomotion) and 2 of 13 mice never recovered walking.

\section{Interlimb coordination of the spinal mouse}

A proper out-of-phase (50\%) coupling between the right and left hindlimbs normally occurred by the day 14 after spinalization. A

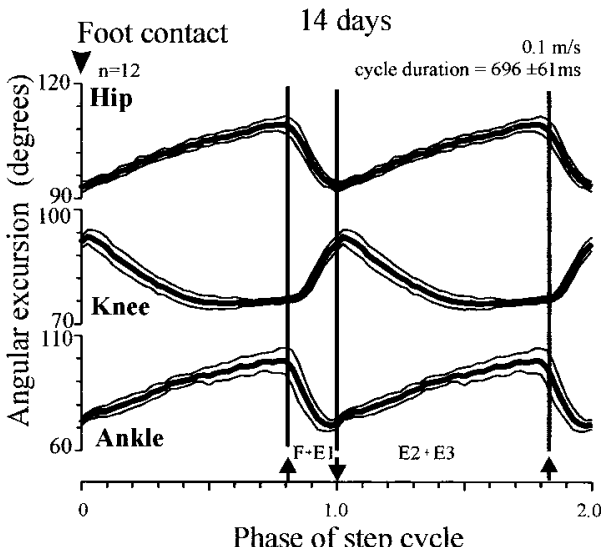

Phase of step cycle

Figure 6. Average angular excursions of a spinal mouse. The averaging of the angular excursions of the hip, knee, and ankle joints of a spinal mouse $14 \mathrm{~d}$ after spinalization are similar to those of an intact mouse (compare Fig. $2 B$ ). This is an averaging of the raw data presented in Figure $5 F$.

typical gait diagram is illustrated in Figure 7 for the same mouse shown in Figure 5. In Figure 7 $A$, only rare appropriate alternation was observed between the right and left hindlimbs $6 \mathrm{~d}$ after spinalization. At this stage, each hindlimb made more or less independent movements. At $12 \mathrm{~d}$ (Fig. 7B), even if a certain amount of correct out-of-phase alternation between the RHL and the LHL was observed, the overall coordination between both sides was still deficient. At this time, it is important to recall that the kinematics of the individual hindlimb is correct (Fig. $5 B$ ). Figure $7 C$ shows the proper alternation between the LHL and the RHL. The mean duration of the step cycle was similar for both limbs, $700 \pm$ 


\section{A. 6 days post spinalisation}

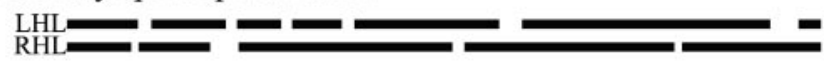

B. 12 days post spinalisation

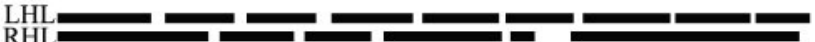

C. 14 days after spinalisation

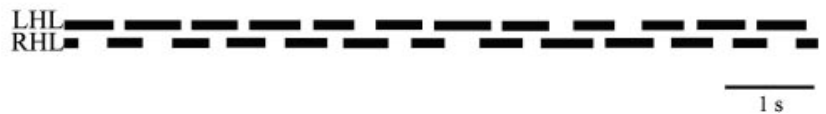

Figure 7. Duty cycle of the hindlimbs of a spinal mouse early after spinalization. A, At $6 \mathrm{~d}$ after the complete section, there is only a poor alternation between the right and left hindlimbs. $B$, At $12 \mathrm{~d}$ after spinalization. C, At $14 \mathrm{~d}$, really good timing between left and right hindlimb was observed during the locomotor movements.

$64 \mathrm{msec}$ for the LHL and $697 \pm 49 \mathrm{msec}$ for the RHL; they acted in strict alternation, as was the case before spinalization (Fig. $3 A, B)$. Indeed, there is no significant difference in mean hindlimb phase values (the homologous coupling) between intact CD1 mice $(0.50 \pm 0.08)$ and spinal mice after recovery of locomotion $(0.46 \pm 0.09)$.

Because the spinal cord was completely severed, the spinal mouse never recovered a constant coupling between the hindlimbs and forelimbs. Figures $8 A-D$ illustrate the gait diagram for the four limbs of a mouse before spinalization (Fig. $8 A$ ) and after spinalization at three different times after recovery: $15 \mathrm{~d}$ (Fig. $8 B$ ), $28 \mathrm{~d}$ (Fig. $8 C$ ), and $51 \mathrm{~d}$ (Fig. $8 D$ ). It is clear that, even if the mouse recovered locomotion of the hindlimbs on a treadmill, the coupling between the hindlimbs and the forelimbs was definitively lost, as indicated by the thin line linking the foot contact of the LHL and the LFL.

This loss of timing is further evidenced by the polar plots in Figures $8 E-G$, which illustrate phase values (here multiplied by $360^{\circ}$ ) between the LFL and the LHL before spinalization (Fig. $8 E$ ) and $28 \mathrm{~d}$ (Fig. $8 F$ ) and $51 \mathrm{~d}$ (Fig. $8 G$ ) after the complete section of the spinal cord. The phase data (black dots) on the diagram are linked by a thin line to determine the exact sequence of the consecutive phase values during locomotion. In the intact mouse, the mean phase value is represented by a vector in which the direction represents the mean phase $(0.32 \pm 0.07$; see LFL vs LHL for mouse 2 in Table 1) and the length indicates the concentration of phase values around the mean. At $28 \mathrm{~d}$ after spinalization (Fig. $8 \mathrm{~F}$ ), the addition of two additional concentric polar plots were necessary because there were phase values over $360^{\circ}(n=3)$ and even over $720^{\circ}(n=1)$. Because of the dispersion of the phase values, no mean phase was calculated (no arrow).

It is important to mention that this lack of coordination between the two girdles is not evident during locomotion by just watching the animal. Without objective measurements of coordination between forelimbs and hindlimbs, and based only on visual observation (especially to the untrained eye), it is possible to conclude incorrectly that the movements are well coordinated.

\section{Discussion}

The results presented show first that the kinematics and EMG of adult normal mice can be documented satisfactorily using conventional video and EMG equipment and, second, that mice can re-express hindlimb locomotion within $14 \mathrm{~d}$ after spinalization without pharmacological treatment.

\section{The kinematics and EMGs of normal mouse locomotion}

The small size of mice may appear to preclude the use of conventional equipment to study kinematics or EMG activity to study locomotion. Overall, mice walked with no difficulty on the treadmill, and could keep up the imposed speed, enabling us to record several consecutive step cycles necessary for averaging. The video recording system used in the cat (Bélanger et al., 1996) and rat (Orsal et al., 2002) could be used to detect the markers on the joints automatically. The use of a conventional 30 frames per second video camera, with the ability to split frames in their two component fields (final temporal resolution, $16.7 \mathrm{msec}$ ), is appropriate for treadmill speeds lower than $0.2 \mathrm{~m} / \mathrm{sec}$. At these speeds, the duration of the swing phase was $\sim 100 \mathrm{msec}$, corresponding to approximately six video fields (three video frames). However, this is at the limit of tolerance to reconstruct the angular movements correctly during the swing phase and the exact timing of foot lift and the foot contact. To study the kinematics at higher treadmill speeds, a high-speed video camera would be more adequate.

In most animals, it is difficult to determine the knee angle accurately because of skin slippage. To minimize this, the knee marker was corrected by triangulation using bone measurements of the femur and tibia. Nevertheless, some slippage could still explain why, in some cases, the extension of the knee joint, characteristic of the E3 phase, was not clearly seen (Fig. 2). Despite these difficulties, the terminology used to describe the step cycle in other animals (Philippson, 1905) can be applied to murine locomotion. Moreover, as is the case for most mammals (Grillner, 1981), the swing phase is rather constant, even with varying speeds, whereas the stance phase varies with speed.

Measurements of foot contact also allowed us to establish the mode of coupling between the limbs and to illustrate the locomotor pattern using gait diagrams (Hildebrand, 1976). The results show that the homologous limbs of both the pelvic and scapular girdles are out of phase by 0.5 , but that the duration of stance of the forelimbs and hindlimbs are different (Clarke and Still, 1999). The gait formula generally follows a sequence of alternation between three and two limbs in contact with the ground. The usual sequence of LH-LF-RH-RF is followed at these low speeds.

Here, we have also shown, in one animal, that it is possible to record satisfactorily from some muscles of the thigh and shank with chronically implanted electrodes. The miniature connectors with the small-diameter wires did not impede locomotion. The overall weight of the connector and wires was $\sim 0.30 \mathrm{gm}$, which represents $\sim 1 \%$ of body weight. The clean signals from EMG recordings could even be used to determine the various phases of the locomotor cycle, as well as the various couplings described above, using kinematic analyses. Work is underway to compare EMG activity in the same mice before and after spinalization.

There are numerous tests designed to assess the locomotor function of rats after spinal cord injury, and all have their merits (Rivlin and Tator, 1977; Kunkel-Bagden et al., 1993; Basso et al., 1995). Most of them rank the locomotor behavior in an openfield situation. The most widely used is the BBB (Basso-BeattieBresnahan scale), which standardizes the ranking on a 21-point locomotor index of over-ground locomotion obtained by observing the locomotor movements of the rats in an open field (Basso et al., 1995). Such scores rely on visual determination of the quality of locomotion and can possibly lead to incorrect interpretations by the untrained eye. For example, we mentioned in our results (Fig. 8) that it is very difficult by visual examination to ascertain that there is a correct coupling between the forelimbs and the hindlimbs during walking after recovery of locomotion in the hindlimbs (see also, Broton et al., 1996). A related problem arose in studies of cats with large but incomplete ventral and ventrolateral lesions at T13 (Brustein and Rossignol, 1998). With 
precise measurements, we showed that the forelimbs and hindlimbs could actually walk at slightly different mean frequencies, which led to periodic stumbling of the animal.

\section{Spinal locomotion in the mouse}

An important result of the present study is that spinal mice can spontaneously recover hindlimb locomotion on a treadmill. This corroborates in vitro studies on neonate mouse spinal cord that demonstrate the existence of a central pattern generator (Bonnot et al., 1998). In the present work, we have ensured also that the recovery of locomotion could not be attributable to some spontaneous regeneration of axons through the lesion. This was achieved by performing a second spinal section at the level of the first lesion at a time when the animal had recovered spinal locomotion. This second spinalization did not affect spinal locomotion or its subsequent evolution.

As in the cat (Barbeau and Rossignol, 1987), the locomotor recovery in the mouse took time. During the first postlesion week, only occasional flexion movements of all joints were observed on the treadmill. At the end of the first week, some alternation between hindlimbs was present with occasional foot placements. Most of the locomotor recovery took place during the second week after spinalization. The normal kinematics of each individual limb was first restored and was followed, 2-3 d later, by a proper out-ofphase alternation between the hindlimbs. Thus, it appears that the spinal networks responsible for locomotion of a given limb can recover to some extent before the interlimb coordination is ensured. This course of evolution between intralimb and interlimb coordination is somewhat different from that in the cat, in which both intralimb kinematics and bilateral alternation appear at the same time after spinalization (Bélanger et al., 1996). After the recovery of locomotor rhythm, the patterns observed in spinal mice remained for the whole period of observation (3-4 months).

Another important feature is the fact that two mice reexpressed locomotion spontaneously without either training or pharmacological treatment. The ability of the spinal mouse to re-express locomotion was surprising because another rodent, the adult rat, is unable to recover locomotion with their hindlimbs after a complete spinal lesion unless neurochemical stimulation is provided either by drugs or cellular grafts (Yakovleff et al., 1989; Broton et al., 1996; McDonald et al., 1999; Gimenez y Ribotta et al., 2000; Antri et al., 2002; Orsal et al., 2002). However, rats spinalized as neonates, can re-express locomotion of the hindlimbs for several weeks after spinalization (Stelzner et al., 1975; Weber and Stelzner, 1977; Commissiong and Sauve, 1993; de Leon et al., 2002).

The differences between rats and mice have already been exposed in studies using isolated spinal cord of neonates in vitro. Indeed, it was shown, by recording EMGs in isolated spinal cord with hindlimbs attached in vitro (Hernandez et al., 1991) or by recording ventral root discharges in isolated low spinal preparation (Branchereau et al., 2000; Whelan et al., 2000), that the lumbar spinal cord of the neonatal mouse has the capacity to generate spontaneously rhythmic locomotor patterns, without any drugs. In contrast, it is not possible to evoke fictive locomotor patterns in neonatal rats without pharmacological activation (Cazalets et al., 1992, 1995; Kiehn and Kjaerulff, 1996). Thus, our results confirm in vivo that the locomotor pattern can be expressed spontaneously.

In the context of a study on spinal cord compression injuries in mice, some mice also had a complete transection of the spinal cord (Farooque, 2000). They were reported to be paraplegic for the observation period of 12 weeks. The mice exhibited some movements of the hindlimbs in the open field but had no coordination or weight support. These movements were attributed to local spinal cord reflexes. In contrast, we have shown in this study that a mouse with a complete spinal cord section can re-express locomotion. However, it is important to note that the spinal mouse, which has a proper pattern of locomotion on the treadmill at $14 \mathrm{~d}$ after spinalization, will look paraplegic if put in an open-field situation (i.e., the hindlimb will simply drag behind the animal and only some occasional movements will be observed). In fact, the animal has to be supported and a lateral stability has to be provided by the experimenter. This does not mean that the spinal cord circuitry does not have the ability to generate locomotor pattern by itself when properly stimulated.

It is hoped that this work will promote the use of standard video and EMG recordings to evaluate the outcome of therapies after spinal cord injury in the mouse by providing a more quantitative assessment of the locomotor movements and the underlying pattern of muscle activity.

\section{References}

Antri M, Orsal D, Barthe J-Y (2002) Locomotor recovery in the chronic spinal rat: effects of long-term treatment with a 5-HT2 agonist. Eur J Neurosci 16:467-476.

Barbeau H, Rossignol S (1987) Recovery of locomotion after chronic spinalization in the adult cat. Brain Res 412:84-95.

Basso DM, Beattie MS, Bresnahan JC (1995) A sensitive and reliable locomotor rating scale for open field testing in rats. J Neurotrauma 12:1-21. Bélanger M, Drew T, Provencher J, Rossignol S (1996) A comparison of 
treadmill locomotion in adult cats before and after spinal transection. J Neurophysiol 76:471-491.

Bonnot A, Morin D, Viala D (1998) Genesis of spontaneous rhythmic motor patterns in the lumbosacral spinal cord of neonate mouse. Brain Res Dev Brain Res 108:89-99.

Bonnot A, Whelan PJ, Mentis GZ, O’Donovan MJ (2002a) Spatiotemporal pattern of motoneuron activation in the rostral lumbar and the sacral segments during locomotor-like activity in the neonatal mouse spinal cord. J Neurosci 22:RC203(1-6).

Bonnot A, Whelan PJ, Mentis GZ, O'Donovan MJ (2002b) Locomotor-like activity generated by the neonatal mouse spinal cord. Brain Res Brain Res Rev 40:141-151.

Branchereau P, Morin D, Bonnot A, Ballion B, Chapron J, Viala D (2000) Development of lumbar rhythmic networks: from embryonic to neonate locomotor-like patterns in the mouse. Brain Res Bull 53:711-718.

Broton JG, Nikolic Z, Suys S, Calancie B (1996) Kinematic analysis of limb position during quadrupedal locomotion in rats. J Neurotrauma 13:409-416.

Brustein E, Rossignol S (1998) Recovery of locomotion after ventral and ventrolateral spinal lesions in the cat. I. Deficits and adaptive mechanisms. J Neurophysiol 80:1245-1267.

Cazalets JR, Sqalli-Houssaini Y, Clarac F (1992) Activation of the central pattern generators for locomotion by serotonin and excitatory amino acids in neonatal rat. J Physiol (Lond) 455:187-204.

Cazalets JR, Borde M, Clarac F (1995) Localization and organization of the central pattern generator for hindlimb locomotion in newborn rat. J Neurosci 15:4943-4951.

Clarke KA, Still J (1999) Gait analysis in the mouse. Physiol Behav 66:723-729.

Clarke KA, Still J (2001) Development and consistency of gait in the mouse. Physiol Behav 73:159-164.

Commissiong JW, Sauve Y (1993) Neurophysiological basis of functional recovery in the neonatal spinalized rat. Exp Brain Res 96:473-479.

de Leon RD, Reinkensmeyer DJ, Timoszyk WK, London NJ, Roy RR, Edgerton VR (2002) Use of robotics in assessing the adaptive capacity of the rat lumbar spinal cord. Prog Brain Res 137:141-150.

Delcomyn F (1980) Neural basis of rhythmic behavior in animals. Science 210:492-498.

Dergham P, Ellezam B, Essagian C, Avedissian H, Lubell WD, McKerracher L (2002) Rho signaling pathway targeted to promote spinal cord repair. J Neurosci 22:6570-6577.

Droge MH, Tao Y (1993) Glycine effects on in vitro motor pattern generation in mouse spinal cord. Neurosci Lett 158:139-142.

Farooque M (2000) Spinal cord compression injury in the mouse: presentation of a model including assessment of motor dysfunction. Acta Neuropathol 100:13-22.

Forssberg H, Grillner S, Halbertsma J (1980) The locomotion of the low spinal cat. I. Coordination within a hindlimb. Acta Physiol Scand 108:269-281.

Fortier P, Smith AM, Rossignol S (1987) Locomotor deficits in the mutant mouse, Lurcher. Exp Brain Res 66:271-286.

Gimenez y Ribotta M, Provencher J, Feraboli-Lohnherr D, Rossignol S, Privat A, Orsal D (2000) Activation of locomotion in adult chronic spinal rats is achieved by transplantation of embryonic raphe cells reinnervating a precise lumbar level. J Neurosci 20:5144-5152.

Grillner S (1981) Control of locomotion in bipeds, tetrapods, and fish. In: Handbook of physiology: the nervous system II (Brookhart JM, Mountcastle VB, eds), pp 1179-1236. Bethesda, MD: American Physiological Society.

Hernandez P, Elbert K, Droge MH (1991) Spontaneous and NMDA evoked motor rhythms in the neonatal mouse spinal cord: an in vitro study with comparisons to in situ activity. Exp Brain Res 85:66-74.

Hildebrand M (1976) Analysis of tetrapod gaits: general considerations and symmetrical gaits. In: Neural control of locomotion (Herman RM, Grillner S, Stein PSG, Stuart DG, eds), pp 203-236. New York: Plenum.
Jiang Z, Carlin KP, Brownstone RM (1999) An in vitro functionally mature mouse spinal cord preparation for the study of spinal motor networks. Brain Res 816:493-499.

Kiehn O, Kjaerulff O (1996) Spatiotemporal characteristics of 5-HT and dopamine-induced rhythmic hindlimb activity in the in vitro neonatal rat. J Neurophysiol 75:1472-1482.

Kjaerulff O, Kiehn O (1996) Distribution of networks generating and coordinating locomotor activity in the neonatal rat spinal cord in vitro: a lesion study. J Neurosci 16:5777-5794.

Kunkel-Bagden E, Dai HN, Bregman BS (1993) Methods to assess the development and recovery of locomotor function after spinal cord injury in rats. Exp Neurol 119:153-164.

Leblond H, L’Espérance M, Orsal D, Guertin P, Provencher J, Lebel F, Rossignol S (2002) Spinal locomotion in paraplegic mouse. Soc Neurosci Abstr 28:664.8.

Lovely RG, Gregor RJ, Roy RR, Edgerton VR (1990) Weight-bearing hindlimb stepping in treadmill-exercised adult spinal cat. Brain Res 514:206-218.

McDonald JW, Liu X-Z, Qu Y, Liu S, Mickey SK, Turetsky D, Gottlieb DI, Choi DW (1999) Transplanted embryonic stem cells survive, differentiate and promote recovery in injured rat spinal cord. Nat Med 5:1410-1412.

Orsal D, Barthe J-Y, Antri M, Feraboli-Lohnherr D, Yakovleff A, Gimenez y Ribotta M, Privat A, Provencher J, Rossignol S (2002) Locomotor recovery in chronic spinal rat: long-term pharmacological treatment or transplantation of embryonic neurons. In: Spinal cord trauma: regeneration, neural repair, and functional recovery (McKerracher L, Doucet G, Rossignol S, eds), pp 213-230. New York: Elsevier.

Philippson M (1905) L'autonomie et la centralisation dans le système nerveux des animaux. Trav Lab Physiol Inst Solvay (Bruxelles) 7:1-208.

Rivlin AS, Tator CH (1977) Objective clinical assessment of motor function after experimental spinal cord injury in the rat. J Neurosurg 47:577-581.

Rossignol S (1996) Neural control of stereotypic limb movements. In: Handbook of physiology, section 12. Exercise: regulation and integration of multiple systems (Rowell LB, Sheperd JT, eds), pp 173-216. New York: Oxford UP.

Rossignol S, Chau C, Giroux N, Brustein E, Bouyer L, Marcoux J, Langlet C, Barthélemy D, Provencher J, Leblond H, Barbeau H, Reader TA (2002) The cat model of spinal injury. In: Spinal cord trauma: regeneration, neural repair, and functional recovery (McKerracher L, Doucet G, Rossignol S, eds), pp 151-168. New York: Elsevier.

Seitz A, Aglow E, Heber-Katz E (2002) Recovery from spinal cord injury: a new transection model in the C57Bl/6 mouse. J Neurosci Res 67:337-345.

Stelzner DJ, Ershler WB, Weber ED (1975) Effects of spinal transection in neonatal and weanling rats: survival of functions. Exp Neurol $46: 156-177$.

Steward O, Schauwecker PE, Guth L, Zhang Z, Fujiki M, Inman D, Wrathall J, Kempermann G, Gage FH, Saatman KE, Raghupathi R, McIntosh T (1999) Genetic approaches to neurotrauma research: opportunities and potential pitfalls of murine models. Exp Neurol 157:19-42.

Tao Y, Droge MH (1992) Comparison of spontaneous motor pattern generation in non-hemisected and hemisected mouse spinal cord. Neurosci Lett 144:116-120.

Van de Meent H, Hamers FP, Lankhorst AJ, Buise MP, Joosten EA, Gispen WH (1996) New assessment techniques for evaluation of posttraumatic spinal cord function in the rat. J Neurotrauma 13:741-754.

Weber ED, Stelzner DJ (1977) Behavioral effects of spinal cord transection in the developing rat. Brain Res 125:241-255.

Whelan P, Bonnot A, O’Donovan MJ (2000) Properties of rhythmic activity generated by the isolated spinal cord of the neonatal mouse. J Neurophysiol 84:2821-2833.

Yakovleff A, Roby-Brami A, Guezard B, Mansour H, Bussel B, Privat A (1989) Locomotion in rats transplanted with noradrenergic neurons. Brain Res Bull 22:115-121.

Zar JH (1996) Biostatistical analysis. Upper Saddle River, NJ: Prentice Hall. 